\title{
Clinical-Laboratory Profile of Child and Young Populations Bit By Scorpion Attended at a Information and Assistance Toxicological Center in Brazil
}

\author{
Naiane Nadylla Nobre Sombra' ${ }^{1}$ Andreza da Silva Soares Pereira ${ }^{1}$, Edilson Martins Rodrigues Neto',* Fernanda Maria Teófilo Campos ${ }^{3}$, \\ Geraldo Bezerra da Silva Júnior ${ }^{4}$, João Augusto Lima Bisneto ${ }^{5}$, Sarah Gabrielle Sousa de Oliveira Rodrigues ${ }^{6}$, Elizabeth De Francesco \\ Daher ${ }^{4}$, Malena Gadelha Cavalcante ${ }^{1,4}$ \\ ${ }^{1}$ Pharmacy Graduation Course, Maurício de Nassau Universitary Center, Fortaleza, CE, BRAZIL. \\ 2Department of Pharmacy, Dentistry and Nursing College, Federal University of Ceara, Fortaleza, CE, BRAZIL. \\ ${ }^{3}$ Pharmacology Post Graduation Program, Mastering Course, Federal University of Ceara, Fortaleza, CE, BRAZIL. \\ ${ }^{4}$ Medical Sciences Post Graduation Program, Medical School of the Federal University of Ceará, Fortaleza, CE, BRAZIL. \\ ${ }^{5}$ School of Medicine, Unichristus, Fortaleza, Ceará, BRAZIL. \\ ${ }^{6}$ Assis Chateaubriand Maternity School- MEAC, Fortaleza, Ceará, BRAZIL.
}

\begin{abstract}
Background: In Brazil, the most relevant scorpions for public health are species of the genus Tityus: T. serrulatus, T. bahiensis, T. obscurus and T. stigmurus, the latter occurring mainly in Ceará, showing that severe cases affect more the population at risk, children under 14 years old. Objectives: The survey aims to identify what are the clinical and laboratory changes in children and teenagers affected by scorpion bites, as well as predictive factors in severe cases. Methods: This is an observational, retrospective and quantitative study of poisoning by scorpion accidents attended and notified by the Toxicological Assistance Center of Fortaleza (CIATOX / CE) from January to December 2019. Results: 820 records were diverted, in which $425(51.83 \%)$ women were killed, of which only $3(0.37 \%)$ were pregnant. Regarding the age group, 1-3 years old is more frequent, 183 (22.32\%). The species T. stigmurus 534 cases, (65.12\%), the feet region 271 cases (33.04\%); the origin of the municipality of Fortaleza 773 (94.15\%) and the regional II 122 cases $(15.78 \%)$ had higher occurrences. Of the 820 cases, only 12 underwent laboratory tests, showing changes such
\end{abstract}

as leukocytosis leukocytosis (72.7\%), platelets (63.6\%), hyperglycemia (83.3\%), TGO (100\%), LDH (100\%), CK - MB (100\%) and Amylase (30\%). Conclusion: It was found that the epidemiological, clinical and laboratory profile of children and adolescentes is associated with the severity of scorpionism, which indicates an emergency characteristic, especially when it affects children.

Keywords: Scorpions, Clinic Epidemiology, Intoxications, Children and youth, Tityus.

\section{Correspondence}

Dr. Edilson Martins Rodrigues Neto,

Department of Pharmacy, Dentistry and Nursing College, Federal University of Ceara, Fortaleza, CE-60020-181, BRAZIL.

Email id: edilsonmrneto@hotmail.com

DOI: 10.5530/jyp.2021.13.50

\section{INTRODUCTION}

All scorpions are animals capable of producing venom and possess the specific apparatus for inoculation regardless of the species. Until the 2020 year, 19 families of scorpions are distributed throughout the world, with the genera Androctonus and Leiurus being largely responsible for the most serious accidents in northern Africa; Centruroides in Mexico and also in the United States; and Tityus, in South America and Trinidad Island. ${ }^{1-5}$

The occurrence of recorded scorpion accidents shows there is an increasing line of cases, in 2016 there were 91.7 thousand cases; in 2017, 125 thousand occurrences were registered and in 2018, a total of 141.4 thousand accidents in Brazil. Although the notification is mandatory throughout the national territory, except for the cases that the victims did not show up for assistance and notification by the referral hospitals. ${ }^{6}$ In Brazil, the geographical distribution of the animal reaches the entire territory, with species of the genus Tityus prevalent - yellow scorpion (T. serrulatus), brown scorpion (T. bahiensis), black scorpion of the amazon (T. obscurus) and northeastern yellow scorpion (T. stigmurus) - the latter occurring mainly in Northeastern states (Alagoas, Bahia, Ceará, Paraíba, Pernambuco, Rio Grande do Norte and Sergipe). ${ }^{6}$
These species have great importance for public health due they are potent causers of several clinical and laboratory alterations, mainly among pediatric population, with severity and clinical evolution generated by the scorpion's bite varying depending on the species of the venomous animal. The clinical picture, with manifestations from local to systemic, is classified as mild accident, moderate accident and serious accident for a determined conduct of clinical management, showing that severe cases affect more the population at risk, such as the elderly and children under 14 years old. ${ }^{1,7}$

The magnitude of the involvement is largely since the venoms produced by scorpions are complex combinations of proteins that have biochemical and neurotoxic profiles that favors great interference in structures and key cellular events for the physiological functions of the human organism, such as sodium and potassium, production of pro-inflammatory mediators and vasoactive substances. ${ }^{8}$

Factors related to the individual such as age group, body location affected and time elapsed from the moment of the bite to hospital care, and factors referring to the animal as a species to which it belongs, size and quantity of injected venom are highly relevant items for assertive characterization of the accident as urgency and / or emergency as well as acting as guides 
for the best therapeutic approach to the victim, especially when they are children and the elderly, whose mortality rate tends to be high. ${ }^{9,10}$

The diagnosis is purely clinical-epidemiological, and the dosage of the circulating toxicant is unnecessary. The signs and symptoms can be characterized in increasing levels of severity: mild degree - pain, paresthesia and sweating at the site of the bite, sometimes piloerection; moderate - severe pain at the bite, mild sweating, nausea, occasional vomiting, tachycardia, tachypnea and mild hypertension; and severe - in addition to the signs and symptoms already mentioned, they present one or more exacerbated manifestations, alternation of agitation with prostration, bradycardia, heart failure, pulmonary edema, shock, convulsions and coma. $^{10}$

Based on the definition of the patient's classification, carried out by means of the presented symptoms, those who fit the mild picture have the protocol of being under clinical observation for $6 \mathrm{hrs}$, with symptomatic treatment: analgesia, cold / warm compress and / or local anesthetic block. The need for administration of antiscorpionic serum, as well as the number of ampoules, occurs when the patient's clinic is moderate degree severity, from 2 to 3 vials, or severe degree with 4 to 6 vials of antiscorpionic serum or intravenous antiarachnid serum, plus 24-hr clinical observation after administration and 12/12-hr exam request. ${ }^{11}$

Complementary exams provide information on the clinical picture of the patient poisoned by the bite of a given species of scorpion that will help the diagnosis and prognosis since the scorpion neurotoxin generates changes in important organic functions, such as the clotting time (CT), the blood count that usually reveals leukocytosis with neutrophilia and left shift, hemosedimentation, thrombocytopenia, electrolytes, urea and creatinine, and there may also be disorders in the urine summary, such as proteinuria, hematuria and leukocyturia. ${ }^{12}$

In this context, the triad clinical examination, laboratory findings and epidemiological data help in the most successful diagnosis and treatment possible. Highlighting its importance through early intervention and timely management, which can reduce mortality and morbidity in cases of scorpion bite poisoning, therefore, it is worth mentioning that people's awareness of the early start of treatment is necessary to reduce mortality rates due to this environmental health risk. ${ }^{13}$

This research aimed to identify clinical, epidemiological and laboratory aspects and predictive factors in moderate and severe cases in manifestations of scorpion poisoning in the juvenile population in a Toxicological Information and Assistance Center (CIATOX), located in the city of Fortaleza from the Ceará state in Brazil. Emergency assessment and treatment for suspected cases of intoxication and poisoning are CIATOX's responsibility in order to save lives.

\section{MATERIALS AND METHODS}

This is an observational, retrospective, descriptive and documentary study with a quantitative approach to intoxications caused by scorpion bites attended and notified by the Toxicological Information and Assistance Center (CIATOX) in Fortaleza - CE, Brazil. This study was previously approved by the Ethics Committee at CAAE number: 41664214.5.0000.5052.

The study was carried out at the Hospital Instituto Doutor José Frota (IJF), wich is the largest Urgency and Emergency hospital in the assistance network of the Municipality of Fortaleza, integrated with the Brazilian Unified Health System (SUS). The Tertiary Level unit is a North and Northeast regions reference in specialized treatment to victims of highly complex traumas, severe vascular injuries, burns and acute intoxications.

The hospital has a center specialized in Caring for Intoxicated Patients or Victims of Accidents with Venomous Animals (CIATOX), composed of pharmacists and doctors, open 24 hrs a day. CIATOX is also a field for undergraduate and postgraduate courses at the Health area.

During the period from January to December 2019, all patients with scorpion bite intoxication aged 18 years or less were analyzed.

Data collection was carried out based on CIATOX electronic records, in which aspects related to the patient, intoxication and the venomous animal are recorded. The variables were studied: Age group, sex, circumstance, severity, clinical manifestations, location of the bite, location where the bite occurred, clinical evolution and treatment.

The programs used for statistical analysis were Microsoft Excel and Epi Info $7^{\circ}$, software in the public domain for the purposes of epidemiological study in the health field. Categorical variables are presented as absolute and relative frequency and numerical variables, as mean and standard deviation, considering the $95 \%$ confidence interval (CI).

Categorical data were collected from the system and expressed as absolute counts with frequency and percentages and were compared using the Chi-square test. In addition, the odds ratio was calculated with the respective $95 \%$ confidence intervals, to assess the power of association between a given factor and the clinical severity of the patients. Significance was accepted when $p<0.05$.

The research required the application of waiver of the Free and Informed Consent Term (ICF), the Term of Commitment to Use Data (TCUD) and the Term of Assent, under the justification that the study is retrospective and used exclusively secondary data, contained in the toxicological records and laboratory tests, not requiring direct contact with patients or with previously stored biological material.

\section{RESULTS}

In this study, 820 patient's victims of scorpionic accidents were registered and analyzed. The municipality of Fortaleza came with 772 individuals (94.15\%), followed by metropolitan regions with 40 victims $(4.8 \%)$, and in lesser attendance from neighboring cities such as Itaitinga, Maracanaú, Amontada, Eusébio, Baturité, Barreira, Capistrano and Redenção, with 8 persons $(1.05 \%)$.

Considering the complementary law $\mathrm{N}^{\circ}$. 278, of December 23, 2019, which regulates the move of Fortaleza division from 6 administrative regions to 12 , it was found that of the 772 victims assisted, regional II had the highest number of cases $15.78 \%$, with the highest number of occurrences in the following neighborhoods: Barra do Ceará (27.86\%), Álvaro Weyne (13.11\%) and Carlito Pamplona (10.65\%). Most of the bites occurred between the months of March (11.10\%) and April (11.71\%).

The epidemiological and demographic characteristics analyzed showed that most cases were female $(51.83 \%)$, of which $0.37 \%$ were pregnant. In relation to the age group, accidents were more frequent in the 1-3 year old age group with 183 occurrences $(22.32 \%) .807$ patients $(98.4 \%)$ were observed in the mild-severity group and 13 patients (1.6\%) in the moderate-severe group, evincing a difference between the two groups.

The T. stigmurus species scorpion was more related to accidents 534 $(65.12 \%)$, being responsible for moderate and severe cases as well. The time between attendance-sting, an important factor for the evolution and severity of the accident, was 1-3 hrs in 591 of the cases $(72.07 \%)$, due to early diagnosis and treatment, correlating with cessation of elevated serum scorpion venom levels, after administration of serotherapy.

The request and execution of laboratory tests occurred in only 12 cases $(1.46 \%)$, of those affected with indicative of systemic clinical manifestations, showing that the ncessity for this conduct is not mandatory to happen in all scorpionic cases.

The statistical significance for the number of ampoules in relation to severity was obtained $p=<0.001$ so that critically ill patients $1(100 \%)$ used $3(100 \%)$ ampoules and those without 26 severity (100\%) were 
$0(100 \%)$, since not all patients are indicative of the administration of antiscorpion serum, but according to the severity classification.

The most recorded location of the victims' bodies was feet - 271 cases (33.04\%) and hands - 254 cases $(30.97 \%)$. There was significance $(\mathrm{p}=0.014)$ concerned to the correlation between severity and sting location in the fingers region, in which no severity cases none was stung at that location, so that the closer to vital organs, the greater the complications and the possibility of effects. Although the sting was not identified in some patients and it resulted in a high probability, one must take into account the size of the effect versus the $\mathrm{p}$ value, avoiding an isolated view biasing (without severity: $1(4 \%)$, severe: $0(0 \%)$; $p$-value $=0.024)$.

The patients aged 1-3 years, more than the half of the cases $(58.33 \%)$ evolved to moderate and severe degree. It was observed that all patients aged 13-18 years old were classified as mild or no severity degree $(40.01 \%)$. It was concluded that age can be considered as a factor for aggravation and evolution based on statistical significance (without severity: $12(48 \%)$, severe: $1(100 \%)$; $p$-value $=0.015)$.

The group of patients who did not need serotherapy corresponded to $99.87 \%$, presenting mild degree, in which $66.88 \%$ did not need clinical observation. In the group of moderate degree, only 2 patients (16.67\%) the serum was not administered, being sufficient in $5(41.67 \%)$ the use of 2 ampoules $p=<0.001$. Supportive use was indicated for 776 patients $(99.23 \%)$ with a $p$-value $=0.041$.

Treatment and non-serious accidents obtained $40 \%$ of the cases. In mild degree cases, $64(8.18 \%)$ of the patients did not need medication use to treat the symptoms, $523(66.88 \%) p=<0.001$ did not require clinical observation and 21 events $(2.69 \%) p=<0.001$ there was no conduct need and the patient was discharged from the hospital. It can be analyzed that the therapeutic conduct is based on clinical manifestations presented and evaluated as predictors of severity.

Clinical manifestations pain and paresthesia were more significant $p$-value $=<0.001$ among patients with low degree. In moderate degree, the most common symptoms were sialorrhea, dyspnea, tachydyspnoea, tachycardia, increased blood pressure, vomiting, sweating, drowsiness and agitation $(p=0.001)$. Although the symptoms presented in moderate degree, sweating, nausea and vomit obtained high values, they appeared in mild degree cases because they are, respectively, local characteristics, usually 1 episode and external causes or arising from the use of any medication without prescription in the hospital.

Local symptoms are less evident in severe degree cases than in mild degree cases. Patients who arrived with mildly classified severity, it was observed that they were more asymptomatic than those without severity $p=<0.001$. Patients in severe cases had sweating, vomit, tachycardia, drowsiness and agitation as symptoms, emphasizing that no local symptoms were observed. Agitation (25.26\%) followed by drowsiness $(59.49 \%)$ stands out more in patients of mild to moderate severity

During the period considered, 820 face-to-face visits by scorpions were recorded at CIATOX-CE. Of the 12 cases, related to the T. stigmurus species, 4 (33.3\%) evolved as mild degree, 7 (58.33\%) as moderate degree and $1(8.33 \%)$ as severe degree. The laboratorial fidings from patients who underwent tests during admission, the most significant changes were leukocytosis $(18,048.33+/-9,658.23)$; platelets $(458,833.33+/$ 247,672); hyperglycemia (226.5 +/- 95.36); TGO 38 (27-78); LDH 548 (460-612); CK-MB 29 (26.5-38.5); and Amylase (72.42 +/- 25.51), triggered by the complex effects of scorpion toxin on the sodium channels of the sympathetic, parasympathetic nervous system and adrenal medulla, with the release of neurotransmitters such as norepinephrine and acetylcholine The laboratorial alterations (Table 1) due to the exposure time, evinced a greater decrease in the number of red blood cells $(p$-value $=0.047)$ than in hemoglobin and hematocrit in patients with more than $3 \mathrm{hrs}$ of the accident occurance compared to the shortest time, statistically significant. Examinations with kidneys evaluation evinced urea increasement and significance alteration of creatinine $(p=0.011)$ over a period of more than $3 \mathrm{hrs}$, with characteristics of manifestations with time-dependent kidney damage by scorpion venom exposure, caused due to tityustoxins and catecholamine release, there is a reduction renal flow.

Muscle damage can be quantified by means of creatinophosphokinase - CPK ( $p=0.002)$ showing a statistical difference in the interference of venom in muscle tissue, mainly due to cardiac manifestations, correlated by mediating the effects of catecholamines on the contraction of vessels and the consequent alteration of blood perfusion in myocardium.

In this study, no change in the normal state of some electrolytes, such as potassium, sodium and calcium, was observed in less than or more than $3 \mathrm{hrs}$, except for chloride $p=0.045$ after 3 hrs of contact with scorpion toxin.

\section{DISCUSSION}

Literature mentions that scorpionic accidents in the urban area can be explained by the migration of scorpions from their natural habitat to the

Table 1: Exposure time $\geq 3 \mathrm{hrs}$

\begin{tabular}{|c|c|c|c|}
\hline & No & Yes & $P$ \\
\hline Gender, & $6(66,7)$ & $1(33,3)$ & 0,310 \\
\hline masculine Age, & $1(1-6)$ & $5(2-5)$ & 0,882 \\
\hline years & $4,48(4,39-4,52)$ & $3,87(0-4,52)$ & 0,047 \\
\hline \multicolumn{4}{|l|}{ HM } \\
\hline HB & $11,2(11-11,9)$ & $9(0-12,6)$ & 0,054 \\
\hline HT & $34,6(33,9-35,3)$ & $28,4(0-36,7)$ & 0,056 \\
\hline PLAQ & $\begin{array}{c}486000(396000- \\
540000)\end{array}$ & $256000(0-561000)$ & 0,138 \\
\hline GLIC & $203(151-280)$ & $294(188-346)$ & 0,322 \\
\hline UR & $33(25-36)$ & $53(53-53)$ & 0,051 \\
\hline CR & $0,6(0,55-0,6)$ & $0,9(0,9-0,9)$ & 0,011 \\
\hline TGO & $38,5(33-78)$ & $20(20-20)$ & 0,404 \\
\hline TG P & $15,5(12-36)$ & $18(18-18)$ & 0,726 \\
\hline $\mathrm{LDH}$ & $548(439-679)$ & $512,5(470-555)$ & 0,686 \\
\hline CPK & $186,5(113-255)$ & $813(813-813)$ & 0,002 \\
\hline $\mathrm{K}+$ & $3,6(3,22-3,95)$ & $3,45(2,9-4)$ & 0,746 \\
\hline $\mathrm{CL}$ & $104(102-106)$ & $111(111-111)$ & 0,045 \\
\hline $\mathrm{CA}$ & $10,1(9,8-10,9)$ & $9,85(9,3-10,4)$ & 0,399 \\
\hline NA & $140(137-142)$ & $143(140-146)$ & 0,208 \\
\hline LIPASE & $29(22-40)$ & $24,5(19-30)$ & 0,526 \\
\hline AMILASE & $77(70-78)$ & $78(50-93)$ & 0,927 \\
\hline TAP & $12,55(11,65-12,6)$ & $11,6(11,6-11,6)$ & 0,632 \\
\hline AP & $82,1(75,05-92,95)$ & $99,6(99,6-99,6)$ & 0,333 \\
\hline INR & $1,12(1,04-1,16)$ & $1(1-1)$ & 0,33 \\
\hline TPTA & $32,9(28,35-34,85)$ & $20,2(20,2-20,2)$ & 0,153 \\
\hline
\end{tabular}


urban area, due to the disordered human occupation in places originally inhabited by these arachnids that, by virtue of their cryptozoic habits, started to live in heaps of garbage and building sites, with favorable conditions of temperature, humidity and availability of food for survival

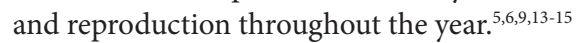

According to data from Cearás 2019-2020 yearbook, the Human Development Index (HDI) indicator for the neighborhoods of Barra do Ceará, Álvaro Weyne and Carlito Pamplona are 0.22 (very low), respectively; 0.36 (average); 0.30 (low). 2010 Census data shows Barra do Ceará concentrating the 2 nd largest population in absolute numbers $(72,423$ inhabitants), with an average income $(\$ 79,78)$ and low education, which can contribute to the favorable conditions for the proliferation of these animals, due to the high production of garbage, and the consequent increase in cockroaches, irregular garbage collection and point, presence of places and deposits of construction material, which favors the neighborhood population more prone to accidents with scorpions. ${ }^{16-18}$

The profile of victims of scorpion accidents reported in CIATOX - IJF was accentuated in female patients aged 7-18 years (263 cases, 63.05\%), most vulnerable, especially in low-income families, in which these girls dedicate themselves household chores, staying at home longer. The data found corroborate with other research carried out in Brazil. ${ }^{13,17}$ However, other studies indicate a large number of cases with scorpionism in males due to their behavior of activities and outdoor play. ${ }^{11}$

The occurrence of scorpionic accidents during all months of the year, as well as their little variation, can be attributed to the climatic conditions of the studied region, characterized by an annual average temperature of $28^{\circ} \mathrm{C}$, varying little between summer and winter, when compared to the South and Southeast. The favorable conditions for the scorpion to proliferate throughout the year would explain the high incidence of accidents with scorpions in Fortaleza. ${ }^{1,18,19}$

In this study, we observed that children under 6 years were most affected by scorpion poisoning, representing $42.81 \%$ of the cases. Another study explains that children tend to be more in contact with these arthropods due to their innocence and curiosities. In CIATOX-PE, from 2006 to 2014, showed that accidents with scorpions were responsible for the highest occurrence $(5,561$ cases $)$ and that children represented $28.8 \%$ of the cases, corresponding mostly to the age group up to 5 years (40.9\%). ${ }^{19}$ As for severity, it is noteworthy that the age group between 1-6 years had the highest severity with moderate (58.33\%) and severe (100\%) cases, in line with results observed in other studies, which associate low age with a worse prognosis, due to the proportion of inoculated poison in relation to the body surface. In this sense, children, especially those under age, generally have higher serum levels of poison; consequently, clinical manifestations are quickly triggered and with greater intensity. The child's physiological aspects can be determinants of severity since he has low immunological capacity and greater absorption of the poison by the heart and other organs. ${ }^{10}$

The time elapsed between the moment of the bite and the hospital assistance showed an association with the greater severity of scorpionism, pointing out that, among moderate patients, $66.17 \%$ sought medical care between 1-6 hrs, although, in the only severe case, patient presented in less than $1 \mathrm{hr}$. Another study analyzed the factors associated with the severity of scorpionism in children and adolescents, when individuals who had more than $3 \mathrm{hrs}$ had a 2.20 times greater chance for the evolution of the clinical picture in relation to those who had less time. ${ }^{4}$

As for the severity with the location of the bite, it was found that, from mild to severe, most accidents affected the feet $(32.19 \%)$ and hands (30.97\%), since the exposure was it happens when the victims put on clothes or shoes. Therefore, as the literature approaches, the closer they are to vital organs, the greater the complications and possibilities of effects. ${ }^{17}$ Into agreement with this, in $50 \%$ of the moderate cases, the inoculation of the poison was in the region of the foot and $100 \%$ of the serious ones in the toe (moderate: $3(25 \%)$, severe: $1(100 \%)$; $p$-value $=0.014)$.

Predictive factors in severe cases were in children under 3 years old, female, with manifestations of local and systemic symptoms in less than $1 \mathrm{hr}$, with a prick in the fingers, evolving to cure with symptomatic and serotherapy after administration of 3 ampoules of it. Thus, the urgency in attending to cases of scorpionism should be considered, emphasizing that the systemic clinical picture can be established within a few minutes to a few hours.

The most frequent local clinical manifestations were pain $(86.95 \%$; $p=0.001)$, paresthesia $(48.17 \% ; p=0.001)$ and nausea / vomiting $(5.85 \%$; $p=0.001)$. The fact that care was provided quickly may explain a greater proportion of mild degree cases. This explains why the majority of accidents did not present indicative symptoms of greater severity, which only $16.82 \%$ of the victims had some systemic complication, serving as a warning to health professionals.

In a previous study, the characteristics of scorpionism in Brazil were evaluated, analyzing clinical and epidemiological factors in the period from 2007 to 2012, presenting results similar to the present study, in which the majority of accidents were clinically mild degree $(82.8 \%)$, with only $1.4 \%$ of severe degree cases. ${ }^{21}$

In clinically moderate individuals treated with antiscorpionic serum (SAEsc) within $3 \mathrm{~h}$ or more of the accident, none had problems with serotherapy. The characterization for not needing serotherapy in mild degree, patients received as treatment only clinical observation (33.12\%), in patients under 6 years old, and treatment of signs and symptoms (91.82\%). As emphasized, cases with mild symptoms require administration of analgesics and antihistamines. However, in cases with systemic symptoms, serotherapy and other measures against anaphylactic reactions are recommended.

Considering the evolution with clinical severity, only 19 individuals $(2.43 \%)$ in mild degree cases had an unconfirmed cure, with no deaths or sequelae in any of the classifications, which has been pointed out in the literature that both the characteristics related to the patient and to the animal influence the evolution. ${ }^{6}$

Among the patients with sérum therapy indicative, it was found that 2 were classified as mild degree, 9 moderate degree and 1 severe degree. On the other hand, another issue that deserves attention is how much the classification of severity occurred in an equivocal manner, making it difficult to characterize the cases. The deficiencies in the medical records are related to the high demand in health centers, the lack of time available to members of the health team or the small number of workers in the health center. ${ }^{17}$

It was observed that, in the subgroup of patients who underwent laboratory tests, the time of exposure to the poison until the administration of the serum greater than or equal to $3 \mathrm{hrs}$ had an influence on the laboratory parameters, altering hematocrit, hemoglobin and erythrocytes, with a tendency to anemia, in addition to in addition, there are increased levels of creatinine and urea ( $p$-value $=0.011)$, indicating kidney damage; CPK was statistically significant $(p$-value $=0.002)$ with evidence of muscle injury.

The literature reports that in multivariate analysis of laboratory parameters such as leukocytes, thrombocytes, glucose, MB fraction of creatinophosphokinase (CK-MB) and CPK, revealed that the most predictive factor for severity was thrombocytosis (odds ratio 23.9; 95\% CI: 1.6-353.5, $\mathrm{P} 1 / 4$ 0.021). ${ }^{2}$ In previous study it was reported that the hematological evaluation is part of the traced profile as well as in important changes such as leukocytosis due to the release of hormones, the action of phar- 
macological mediators in blood cells, reduction of hematocrit, among others. ${ }^{22}$

Despite the low incidence of moderate or severe degree cases of scorpionism by T. stigmurus in the State of Ceará, laboratory tests have been associated with relevant clinical conditions and laboratory changes indicative of cardiotoxicity, hemolysis, hyperglycemic and pro-inflammatory activity, especially in children, found in other studies. ${ }^{2}$

\section{CONCLUSION}

There was a strong predominance of scorpionism in urban areas, mainly in neighborhoods where basic sanitation and more precarious socioeconomic conditions and intense population density in relation to the geographical area were evident.

The age group is considered as a predictive factor given characteristics intrinsic to children under 6 years old, in which the majority develop systemic symptoms faster, although the body location also plays a fundamental role. The importance of hospital care in the shortest possible time is related to a better prognosis and evolution of the patient, in view of the need to administer the antivenom, in amounts recommended according to the classified severity, and appropriate care.

For detailed visualization of the clinical picture and the evolution of patients, in moderate or severe degree condition, it is necessary to have frequent laboratory monitoring, which in scorpionism reveals, on admission, changes such as cardiotoxicity, hemolysis, hyperglycemic and pro-inflammatory, especially in children.

The data presented indicates that investment actions both in the environmental management and in the learning process of the population and health professionals are essential to reduce mortality and morbidity scorpionism. It is noteworthy that the limitations were the possible flaws in the filling and typing of the toxicological notification forms, which can reach the results of the analyzes at the local level. Although such errors are considered, they do not cancel out the results achieved, taking into account the numerical relevance of the sample used during the study period.

The medical literature presents indisputable epidemiological, clinical and laboratory data, with strong similarities with the present study, which makes this work a source for future research in Brazil and other countries with several very pertinent clarifications about accidents with scorpions.

\section{ACKNOWLEDGEMENT}

We thank Dr José Frota Institute.

\section{CONFLICT OF INTEREST}

The authors declare no conflict of interest.

\section{ABBREVIATIONS}

CIATOX : Toxicological Assistance Center of Fortaleza; CPK: Creatinophosphokinase; CT: Clotting time; ICF: Consent Term; IJF: Hospital Instituto Doutor José Frota; SAEsc: Antiscorpionic serum; SUS: Unified Health System; TCUD: Term of Commitment to Use Data.

\section{REFERENCES}

1. AlBuQueRQue CMRD, SANTANA Neto Pde L, AMORIM MLP, PIRES SCV. Pediatric epidemiological aspects of scorpionism and report on fatal cases from
Tityus stigmurus stings (Scorpiones: Buthidae) in State of Pernambuco, Brazil. Rev Soc Bras Med Trop. 2013;46(4):484-9. doi: 10.1590/0037-8682-0089-2013 PMID 23970312

2. ÇAGLAR A, Köse $H$, Babayigit $A$, Öner $T$, Duman $M$. Predictive factors for determining the clinical severity of pediatric scorpion envenomation cases in Southeastern Turkey. Wilderness Environ Med. 2015;26(4):451-8. doi: 10.1016/j. wem.2015.04.005, PMID 26432426.

3. FURTADO SS, BELMINO JF, DINIZ AG, LEITE RS. Epidemiologia do envenenamento por escorpiões no Estado do Ceará. Nordeste do Brasil. Rev Inst Med Trop. 2016;58:15.

4. HORTA FMB, Caldeira AP, Sares JA. Scorpion poisoning among children and adolescents: clinical and epidemiological characteristics of hospitalized patients Rev Soc Bras Med Trop, JAS. Escorpionismo em crianças e adolescentes: aspectos clínicos e epidemiológicos de pacientes hospitalizados. 2007;40(3):351-3. doi: 10.1590/s0037-86822007000300022, PMID 17653477.

5. Yılmaz F ARSLAN ED, DEMIR A, Kavalci C, Durdu T, Yılmaz MS, Yel C, Akbulut S Epidemiologic and clinical characteristics and outcomes of scorpion sting in the southeastern region of Turkey. Ulus Travma Acil Cerrahi Derg. 2013;19(5):417-22. doi: 10.5505/tjtes.2013.52333, PMID 24214782.

6. SOCIEDADE BRASILEIRA DE MEDICINATROPICAL. Acidentes com escorpião. [Available in] [cited 31/3/2021]. Available from: https://www.sbmt.org.br/portal/ accidents-with-scorpions-significant-increase-worries-authorities-and-population/.

7. PARDAL PPO GM. Acidentes por animais peçonhentos: manual de rotina Belém: SESPA -Secretaria de Estado de Saúde Pública do Pará; 2010.

8. EZQUER MR, VILLARREAL M, MUNTANER J. Scorpionism in children in Tucumán: descriptive analysis of cases in a second level of complexity Hospital. Arch Argent Pediatr. 2016;114(6):e413-6. doi: 10.5546/aap.2016.e413, PMID 27869422.

9. BRASIL, Ministério da Saúde. Acidentes por animais peçonhentos. Available in [cited 31/3/2021]. Available from: https://saude.gov.br/saude-de-a-z/acidentespor-animais-peconhentos.

10. CARMO ÉA, NERY AA, PEREIRA R, RIOS MA, CASOTTI CA. Factors associated with the severity of Scorpio poisoning. Texto contexto - enferm. 2019;28(1):3-14 doi: 10.1590/1980-265x-tce-2017-0561.

11. CHIPPAUX JP. Emerging options for the management of scorpion stings. Drug Des Devel Ther. 2012;6(1):165-73. doi: 10.2147/DDDT.S24754, PMID 22826633

12. FUNDAÇÃO NACIONAL DE SAÚDE. Manual de diagnóstico e tratamento de acidentes por animais peçonhentos Brasília, editor. Vol. 2; 2001.

13. SUBRAHMANYAM GVS, VARAHALA AM, CHANDRAIAH D, AMRUTHA PR. Clinical profile of envenomation in children with reference to scorpion sting. $J$ Dent Med Sci. 2016;15(1):38-43.

14. NODARI FR, LEITE ML, NASCIMENTO E. Aspectos demográficos, espaciais e temporais dos acidentes escorpiônicos ocorridos na área de abrangência da $3^{\text {a }}$ Regional de Saúde - Ponta Grossa, PR, no período de 2001-2004. Publ UEPG Cienc Biol Saúde. 2006;12(1):15-26

15. SINITOX/CICT/FIOCRUZ. Série prevenindo intoxicações. Available in. Available from: http://www.ccs.saude.gov.br/visa/publicacoes/arquivos/medicamentos.pdf Acessed: 32/03/2021

16. AZEVEDO R et al. Epidemiologia do envenenamento do escorpião no estado do Ceará. Nordeste do Brasil: Casos subnotificados e superestimados baseados na distribuição geográfica das espécies. Pesqui Ensino Cienc Exatas Natureza. $2017 ; 1(2)$

17. Barros RM, Pasquino JA, Peixoto LR, Targino IT, de Sousa JA, Leite Rde S. Clinical and epidemiological aspects of scorpion stings in the northeast region of Brazil. Cien Saúde Colet. 2014;19(4):1275-82. doi: 10.1590/1413-81232014194. 01602013. PMID 24820610

18. BIG. Data. Anuário do Ceará. Available in. Available from: https://www.anuariodoceara.com.br/fortalezaAcessesed:14/11/2020

19. ALBUQUERQUE PLMM. Intoxicações agudas: guia prático para o tratamento. 1. Ed. Fortaleza: Soneto Editora, 2017.

20. ALMEIDA TS, FOOK SM, FRANCA FO, Monteiro TM, Silva EL, Gomes LC, Farias AM. Spatial distribution of scorpions according to the socioeconomic conditions in Campina Grande, State of Paraíba, Brazil. Rev Soc Bras Med Trop. 2016;49(4):477-85. doi: 10.1590/0037-8682-0128-2016, PMID 27598635.

21. RECKZIEGEL GC, PINTO VL. Scorpionism in Brazil in the years 2000 to 2012. J Venom Anim Toxins Incl Trop Dis. 2014:20(1):46. doi: 10.1186/1678-9199-20-46, PMID 25873937.

22. GUIMARÃES PTC, Pinto MCL, Melo MM. Perfis clínico e hematológico de camundongos submetidos ao envenenamento escorpiônico experimental por Tityus fasciolatus. Arq Bras Med Vet Zootec. 2011;63(6):1382-90. doi: 10.1590/ S0102-09352011000600015. 